\title{
Comparison of the Optical Amplifiers EDFA and SOA Based on the BER and Q-Factor in C-Band
}

\author{
Tomáš Ivaniga $^{1}$ and Petr Ivaniga ${ }^{2}$ \\ ${ }^{1}$ Department of Electronics and Multimedia Communications, Faculty of Electrical Engineering and Informatics, \\ University of Technology Košice, Košice, Slovakia \\ ${ }^{2}$ Department of Information Networks, Faculty of Management Science and Informatics, University of Žilina, Žilina, Slovakia
}

Correspondence should be addressed to Tomáš Ivaniga; tomas.ivaniga@tuke.sk

Received 30 August 2016; Revised 12 December 2016; Accepted 15 December 2016; Published 9 January 2017

Academic Editor: Augusto Beléndez

Copyright (C) 2017 T. Ivaniga and P. Ivaniga. This is an open access article distributed under the Creative Commons Attribution License, which permits unrestricted use, distribution, and reproduction in any medium, provided the original work is properly cited.

Currently it is not possible to create a fully optical communication system without a software tool which simulates an optical communication line in real conditions prior to its construction. The aim of this article is to establish a comparison between the EDFA (erbium doped fibre amplifier) and SOA (semiconductor optical amplifier) optical amplifiers in the WDM (wavelength division multiplexing) system. The system contains a four-channel WDM with speed of $10 \mathrm{Gbps}$ and optical fibre with length of $80 \mathrm{~km}$. Simulations are conducted in the programme environment "OptSim." The quality of the optical communication system is evaluated by the BER (bit error rate) and Q-factor for individual wavelengths, namely, of $1558 \mathrm{~nm}$ and $1562 \mathrm{~nm}$, which are within the C-band.

\section{Introduction}

With the increasing need for higher transfer speeds and greater quantity of transferred data, the optical cable lines are reaching their limits of transfer capacities. One of the options for more effective usage of optical lines is wavelength multiplexing. Using a transfer speed of $10 \mathrm{Gbps}$ (STM-64) with the help of WDM, 128 spectral channels achieving a transfer speed of 1 Tbps could be created in one optical fibre $[1,2]$. Because transferring of the optical signal over great distances leads to its attenuation, the transmission path contains optical amplifiers. In optical communication the EDFA fibre amplifiers, SOA semiconductor amplifiers, or amplifiers based on the Raman effect are the most widely used ones [2-4]. In the second chapter the WDM standard and its division are described. The third chapter is devoted to the error rate BER and related Q-factor. The fourth chapter describes EDFA and SOA optical amplifiers and their basic principles. In the last chapter a simulation is created for the comparison of BER and Q-factor while evaluating the properties of the optical amplifiers.

\section{Wavelength Multiplex}

WDM is based on the idea of combining several optical signals into one optical fibre with usage of different wavelengths for transmitting each of these signals. The transmitter modulates the information for each of the used frequencies. All the contributions from $n$-channels are combined into one optical fibre in the multiplex. A simplified principle is shown on Figure 1.

Techniques of WDM could be divided into three groups: WWDM (wide wavelength division multiplex), DWDM (dense wavelength division multiplex), and CWDM (coarse wavelength division multiplex).

WWDM belongs to the older types and it is frequently used mainly because of its cost-effectiveness. Four mostly utilized wavelengths have a spacing of information-bearing greater than or equal to $20 \mathrm{~nm}$.

DWDM is the most widely used system for backbone lines [5]. The spacing between information-bearing wavelengths is only $0.8 \mathrm{~nm}$ and with increased frequency, a spacing of $0.4 \mathrm{~nm}$ can be encountered. Nowadays systems known as 


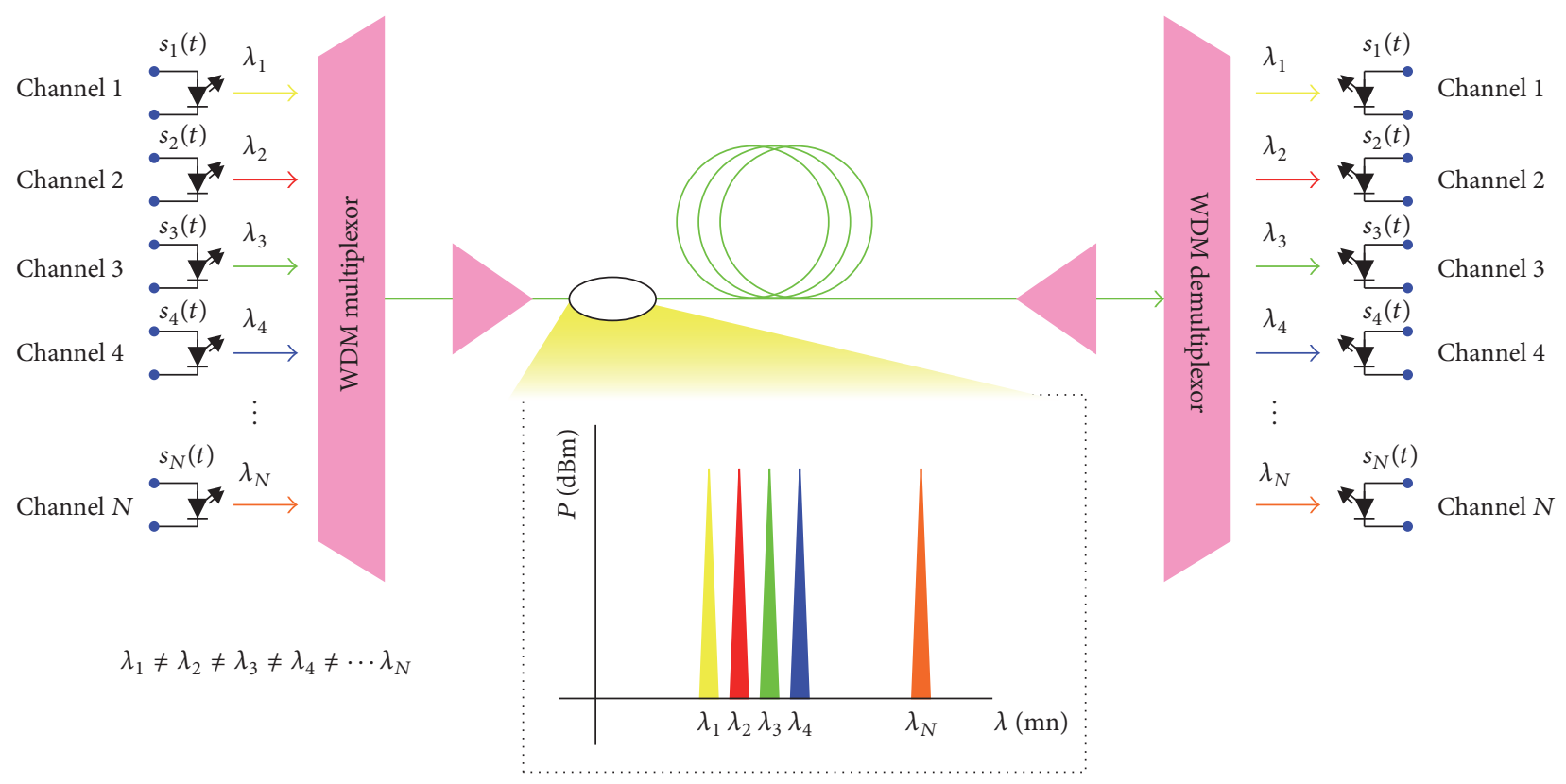

FIGURE 1: Simplified principle of WDM.

UDWDM (ultradense wavelength division multiplex) also exist. These systems utilize spacing of only $0.2 \mathrm{~nm}$ or even $0.1 \mathrm{~nm}$. However decreasing values of spacing place bigger demands on the components being used in transmission path, mostly on the DFB (Distributed Feedback) lasers. Thanks to DWDM systems it is possible to transfer tens or hundreds of parallel optical lines. Recommendation ITUT G.694.1 specifies individual transfer channels within the wavelength range from $1490 \mathrm{~nm}(200.95 \mathrm{THz})$ to $1620 \mathrm{~nm}$ $(186 \mathrm{THz})$, which are included in S, C, or L band [5-7]. DWDM is defined by its normalised frequency of $193.1 \mathrm{THz}$. For correct functioning it is necessary for the wavelength not to diverge from the normalised wavelength by more than $\pm 0.16 \mathrm{~nm}$.

CWDM emerged as a cheaper variation of DWDM. The requirements placed on components used for CWDM are not as strict and technologically demanding as for DWDM components. Spacing between individual channels is according to the recommendation ITU-T G.694.2 stated as $20 \mathrm{~nm}$ so it is possible to use laser diodes without cooling requirements $[8,9]$. The overall tolerated variance from the nominal wavelength is within $\pm 6-7 \mathrm{~nm}$. CWDM enables a transfer of 18 channels while using type G.652.D fibre.

\section{BER and $Q$-Factor}

Q-factor defines the analogue quality of the digital signal with regard to SNR (Signal to Noise Ratio). It contains all physical deterioration factors degrading the signal and causing BER $[3,10]$. The higher the value of $Q$-factor is, the lower the value of BER is (Figure 2). Q-factor is defined by the following:

$$
Q=\frac{I_{1}-I_{0}}{\sigma_{1}-\sigma_{0}},
$$

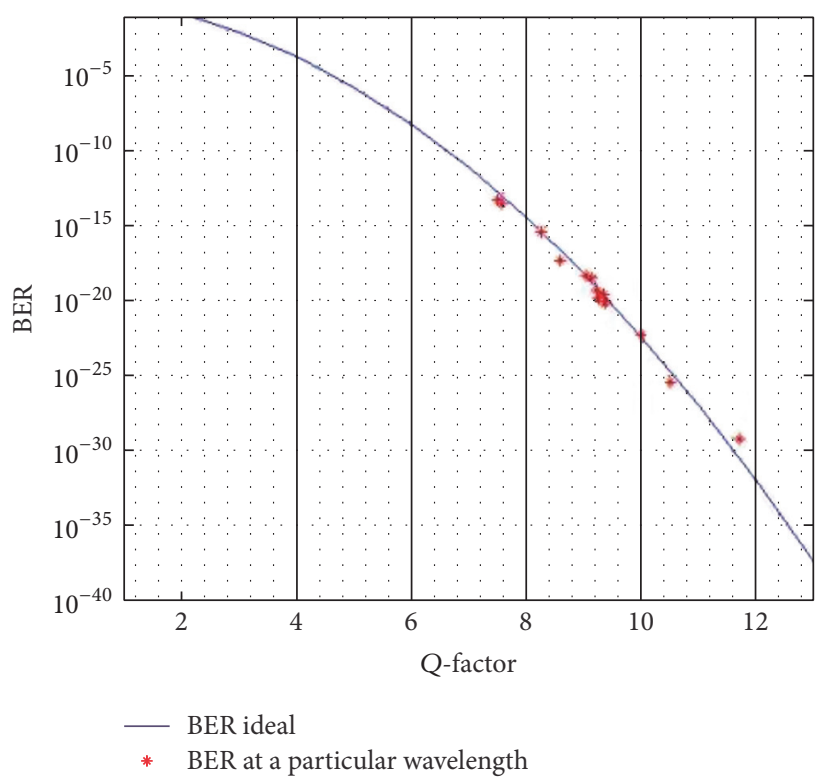

FIgURE 2: Ideal and simulated BER values and $Q$-factor.

where $I_{1}$ represents the logical level " 1 ," $I_{0}$ represents logical level " 0 ," $\sigma_{1}$ represents standard variance of logical level " 1 ," and $\sigma_{0}$ represents standard variance of logical level " 0 ."

BER is defined by the ratio of defectively received bits $b E$ to the overall amount of received bits $p$ in time $t$ :

$$
\mathrm{BER}=\frac{b E}{v p \cdot t} .
$$

Error rate is among basic indicators of quality of the optical transfer. In real optical communication systems the nonzero likelihood of error decision or sample value is 


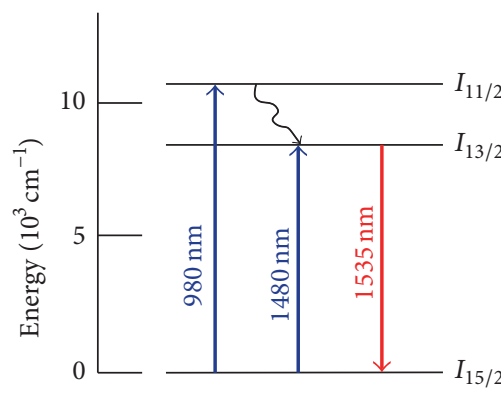

(a)

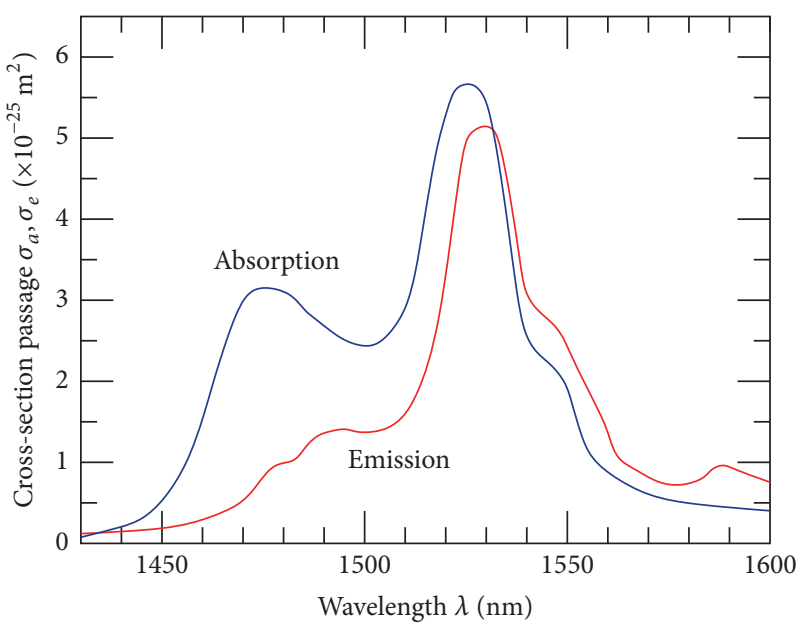

(b)

FIGURE 3: (a) Energy levels of erbium and (b) absorption and emission spectrum of transition ${ }^{4} I_{15 / 2} \leftrightarrow{ }^{4} I_{13 / 2}$.

represented by the value of logical “0” or logical "1" $[3,11,12]$. In real optical communication the BER should be around $10^{-12}$. The BER calculation taking into consideration the $Q^{-}$ factor is defined as

$$
\operatorname{BER}=\frac{1}{2} \operatorname{erfc}\left(\frac{Q}{\sqrt{2}}\right) \approx \frac{\exp \left(-Q^{2} / 2\right)}{Q \cdot \sqrt{2 \pi}} .
$$

A script was created in "Matlab" for the BER calculation as a Q-factor function for the 16-channel DWDM system according to ITU-T G.694.1 (Figure 2).

\section{Optical Amplifiers EDFA and SOA}

Optical amplifiers are frequently used components for wavelength division multiplex systems. In contrast with repeaters, they enable restoration of the light flow in the fibre without the necessity of conversion into electrical form. They are universal components amplifying analogue and numeric signals at any arbitrary transfer speed [13]. Currently there are optical SOA semiconductor amplifiers, EDFA fibre amplifiers, and amplifiers in the bases of the Raman effect.

4.1. EDFA. EDFA consists of a fibre doped by erbium ions of the energy level $\mathrm{Er}^{3+}$. Energy levels important for the amplification of the optical signal in $1.5 \mu \mathrm{m}$ band are shown in Figure 3(a). In Figure 3(a) metastable level is ${ }^{4} I_{13 / 2}$, which can be utilized either directly on $1480 \mathrm{~nm}$ or through the level of ${ }^{4} I_{11 / 2}$ on $980 \mathrm{~nm}$. The lifespan of an ion on level ${ }^{4} I_{11 / 2}$ is very short (approximately $7 \mu \mathrm{s}$ ) in comparison with the lifespan on level ${ }^{4} I_{13 / 2}$ (approximately $10 \mathrm{~ms}$ ), so the ion excited to the level ${ }^{4} I_{11 / 2}$ goes quickly through to the metastable level ${ }^{4} I_{13 / 2}$. Individual levels are marked according to the RussellSaunders convention based on the quantum atomic theory. Expansion of levels shown in Figure 3(b) illustrated the shape of the absorption and emission transition spectrum ${ }^{4} I_{15 / 2} \leftrightarrow$ ${ }^{4} I_{13 / 2}$ in erbium doped optical fibre [13].
The inseparable part is a pair of optical isolators where the isolator prevents the radiation created by spontaneous emission which corrupts the amplification at input. The second isolator at the output prevents the transmission of laser rays and consequently any possible damage to the amplifier itself as the rays are reflected back into the amplifier (Figure 4). A combination of several key factors made the EDFA amplifier choice number one for today's optical communication systems based on the WDM technology [14, 15]. Its most important factors are the following: compact and highly effective semiconductor laser pumps, polarizing independence, simplicity of the device, and the nonexistence of mutual cross-talk while amplifying the WDM signals.

4.2. SOA. The main difference between the SOA and EDFA amplifiers is the active area where the gain generation happens. In the EDFA case it is generated directly in the optical fibre but in the case of SOA it happens directly in the structure of the semiconductor. Another important difference is the principle of energy supply which is used for obtaining the amplification (in the EDFA case it is via laser pump). In SOA the energy is supplied by electrical excitation current. Figure 5 is a schematic portrayal of SOA. The input signal is amplified on whole active area due to a coherent semiconductor stimulated emission. The principle of light amplification through SOA is based on the recombining electrons and holes at the transition of $p$ - $n$ structure.

The semiconductor amplifiers are made as chip in an enclosed case able to keep a constant temperature. By regulating temperature it is possible to set appropriate wavelength to obtain maximum gain. SOA are similar to lasers in their construction and functioning principle but with one fundamental difference. SOA amplifiers contain antireflex layer against creation of resonance and the signal accumulation within the medium. During construction the most important thing is the choice of a semiconductor material with good quantum efficiency. Quantum efficiency is defined 


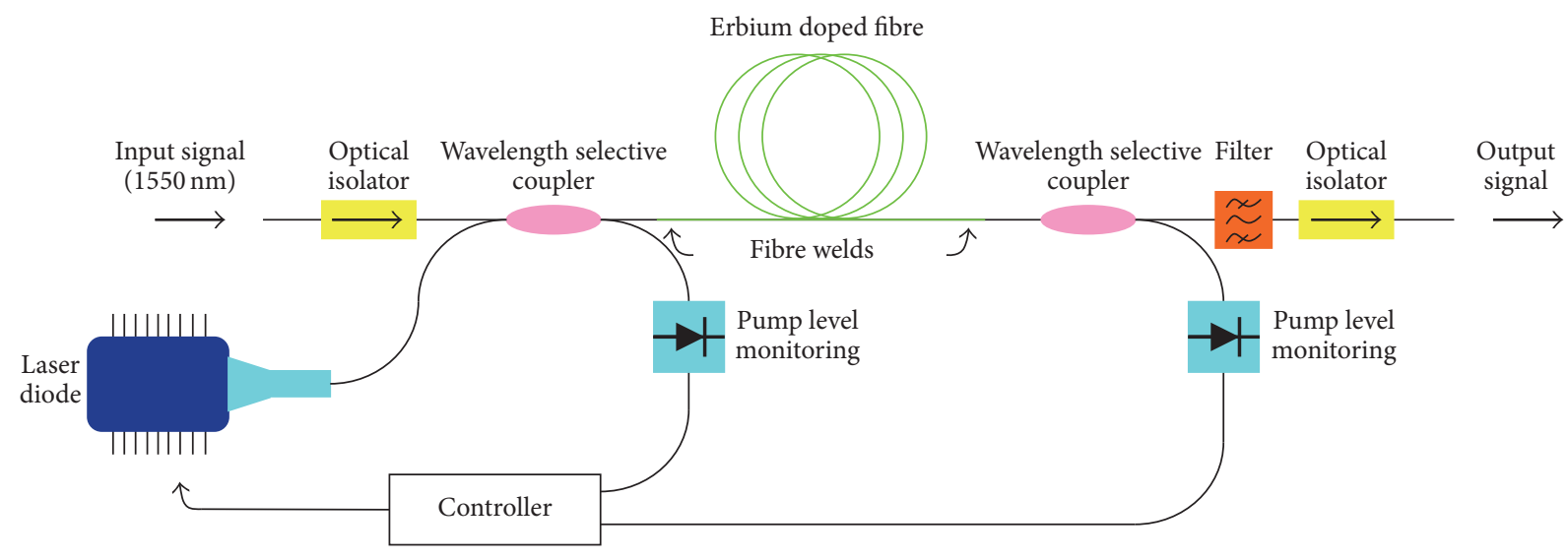

FIGURE 4: Scheme of EDFA connection.

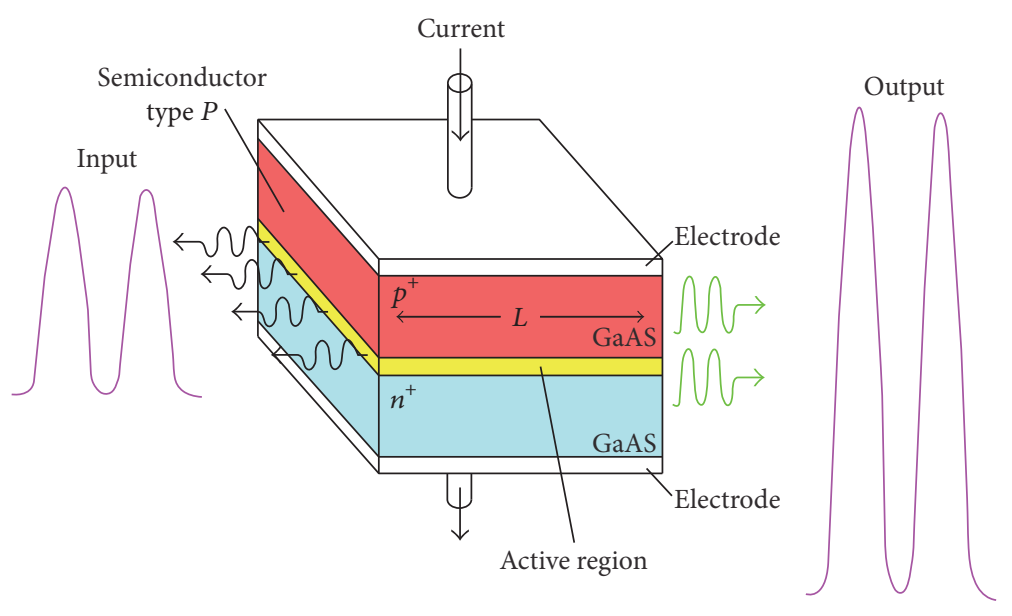

FIGURE 5: Schematic organisation of SOA.

as a ratio between maximal amount of generated photons to the number of excited charges of the carrier [16]. Among applicable elements for the construction are the following: arsenic (As), gallium (Ga), aluminium (Al), indium (In), and phosphor $(\mathrm{P})$. The used materials are the alloys of these elements: GaAs, AlGaAS, InGaAs, InGaAsP, InAlGaAs, and InP.

4.2.1. Principle of the Stimulated Emission in SOA. Stimulated emission precedes stimulated absorption which happens when the absorbed energy is passed on to the electron in a higher valence band of the semiconductor because of the subsequent excitation of that electron to a higher energy level in conductivity band. Excitation of the medium happens as a result of the current of electric energy in our case via electrode connected to the semiconductor. In case of a considerable electron population being on the higher energy level, a population inversion is made. It is a base for the stimulated emission of more photons [16-18]. Photons radiated at stimulated emission are highly coherent and have the same direction and phase as the stimulating ray. The principle of the stimulated emission and population inversion can be seen in Figure 6.

4.2.2. Usage of SOA. Because of simple integration of the amplifier into the receiver, the SOA is often used as a preamplifier when the signal is amplified just before it reaches the receiver. In the same way APD (Avalanche Photodiode) adds additional noise to the signal; the preamplifiers degrade the SNR spacing thanks to the noise of the spontaneous emission. The SOA has a relatively high noise value $\left(F_{n}=\right.$ $5-8 \mathrm{~dB})$ compared to the EDFA $\left(F_{n}=4 \mathrm{~dB}\right)$. However, it is difficult to obtain power levels higher than $10 \mathrm{~mW}$ due to relatively small values of the output saturation power which are around $5 \mathrm{~mW}$. Although the SOA can be used to amplify several channels simultaneously, their greater usage in WDM is hampered by their basic problem of relatively quick response. In the ideal case the signal from individual channels is amplified with constant gain $[13,18]$. Parameters like sensitivity, nonlinear effects, polarization, and high junction losses make these amplifiers harder to use than the in-line amplifiers. The advantage against the EDFA 


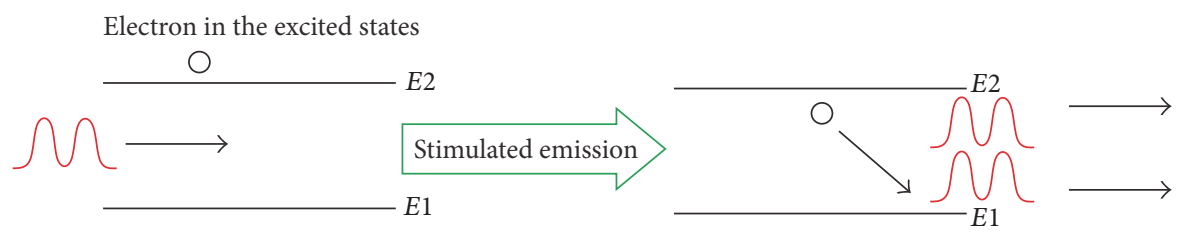

(a)
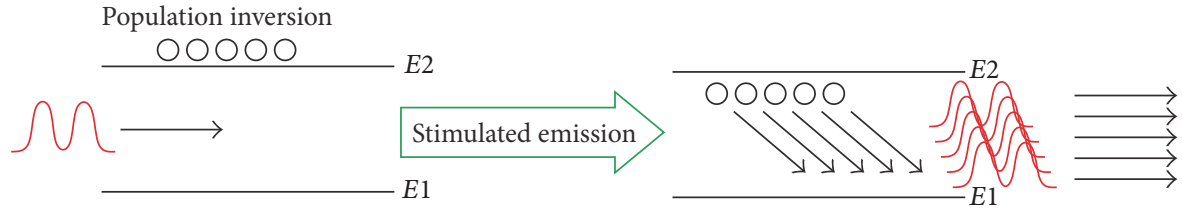

(b)

FIgURE 6: The principle of the stimulated emission.

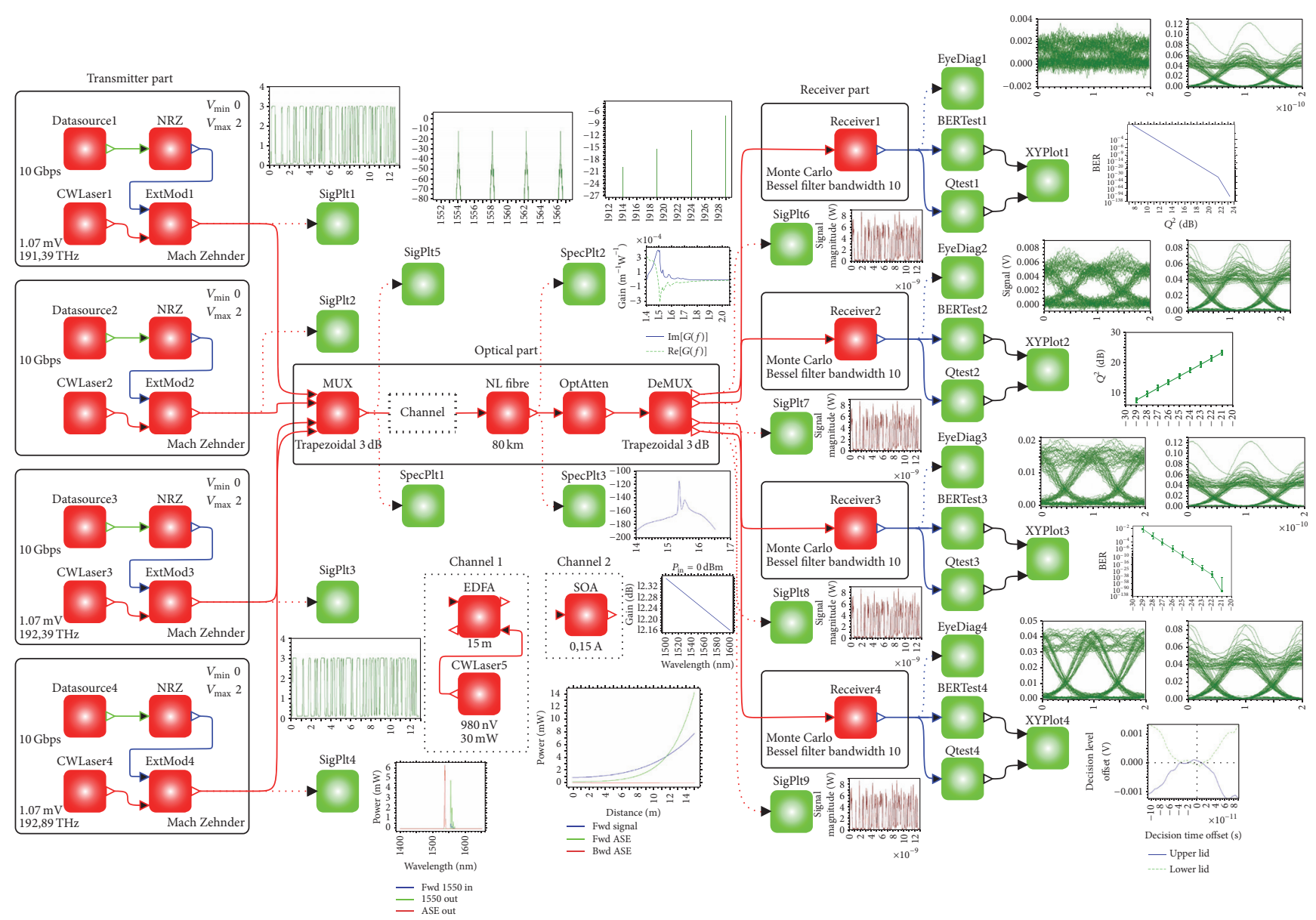

FIGURE 7: Four-channel WDM system.

is usable band of wavelengths from $1280 \mathrm{~nm}$ to $1650 \mathrm{~nm}$. But the EDFA has proved to be more preferable to amplify the signal in the fully optical communication systems thanks to their better parameters. The SOA are utilized as a fast switch for routing in WDM. They are often used as a cheaper option of the optical amplifiers in metropolitan optical networks.

\section{Design of the DWDM System for the Comparison of EDFA and SOA}

Four-channel WDM system was created in the programme environment "OptSim" for purposes of comparing the BER and Q-factor (Figure 7). 
5.1. Achieved Results. As DWDM standard is still being developed and there is compressing of individual channels, it is necessary to prevent FWM (Four-Wave Mixing) and select appropriate spacing between the channels. Ahmed et al., 2014, designed 8-channel DWDM system to observe FWM phenomena while changing various parameters (input power, channel spacing, number of channels, optical gain, core size, RZ and NRZ modulation, and bit rate). Based on the article, we have created DWDM system with spacing of $50 \mathrm{GHz}$ between individual channels in C-band. When using $12.5 \mathrm{GHz}$ and $25 \mathrm{GHz}$, FWM started to be significantly affected [19]. Ivaniga et al., 2015, created 8-channel and 16channel WDM system to compare two codes, NRZ and Miller code, which affected SPM (self-phase modulation) phenomenon at a fibre length of $100 \mathrm{~km}$. The results obtained in the article were used for setting of broadcast channels, and NRZ code was used for better error rate [20]. Pump current for SOA has been selected on the basis of achieved results [21]. BER ranged from $1 \cdot 10^{-4}$ to $1 \cdot 10^{-12}$. From the results published in this article SOA amplifier was designed in order to reach the best error rate for particular wavelengths [21]. The EDFA parameter settings and the length of erbium doped fibre have been designed on the basis of [22]. Obtained results helped to design individual components [22]. Olonkins et al., 2012, created DWDM system and compared SOA and DRA at distances of $112 \mathrm{~km}$ and $119 \mathrm{~km}$ with BER of about $1 \cdot 10^{-13}$ [23].

Anderson compared optical amplifiers in terms of location in the transmission path. Three ways of using SOA and EDFA were used, and these are the preamplifier, booster, and in-line amplifier. Results of simulations for EDFA were better than the ones for SOA [24]. BER for in-line amplifier in EDFA ranged about $1 \cdot 10^{-10}$; the fibre length was $20 \mathrm{~km}$ and DCF was $5 \mathrm{~km}$ [24]. The measurement on a real CWDM device with EDFA-SOA was published [25]. Total distance of optical fibre is $65 \mathrm{~km}$ with attenuation of $0.2 \mathrm{~dB}$ and BER of about $1 \cdot 10^{-9}$. This configuration is suitable for MAN (Metro Access Network) [25]. The comparison of optical amplifiers was based on the location of optical communication systems, in which EDFA and SOA were used as booster in our simulation.

5.2. Design DWDM with EDFA and SOA. In the topology there are three junction lines. The red junction represents the optical signal, the blue one represents electrical signal, and the green junction illustrates the logical signal [2628]. The whole optical communication system contains 4 transmission lines. Every optical transmitter contains 4 basic blocks. The data source generates a bit rate of " $10 \mathrm{Gbps"} \mathrm{in}$ every optical transmitter. The logic signal enters the electrical generator. There is the drive type set to "on-off ramp," using the modulation of type "NRZ" (Nonreturn to Zero) and the "RingFilter" is used with the value of $f_{0}$ set to " $20 \mathrm{MHz}$." The CW (Continuous Wave) laser is placed in the transmitter. Every CW has a Peak Power set to " $1.07 \mathrm{~mW}$ " and the frequency of the first transmitter is " $191.39 \mathrm{THz}$ " while the spacing between the channels is " $4 \mathrm{~nm}$." The last block in every transmitter is the external modulator. Every modulator is set to the modulation of type "Mach Zehnder" while the insertion loss has the value of " $5 \mathrm{~dB}$ " and the chirp factor is "0.5." As it is shown in Figure 1, all optical lines enter the optical multiplex where the individual optical wavelengths are combined.

Optical multiplex has a representation set to "MultiBand" with loss of " $3 \mathrm{~dB}$ " while the type of the filter is "Trapezoidal." Other blocks represent the comparison of EDFA and SOA which were variable during the simulation. In Figure 7 it is shown as Channel 1 and Channel 2, respectively. The laser pump setting for EDFA was the Peak Power equal to " $0.03 \mathrm{~W}$ " and it worked on wavelength of " $980 \mathrm{~nm}$." The length of the erbium doped fibre was $15 \mathrm{~m}$ and fibre saturation parameter was equal to $1 \cdot 10^{15} \mathrm{~m}^{-1} \mathrm{~s}^{-1}$. In our simulation, fibre background loss was neglected, so the parameter background loss was set to " 0 ." The numerical integration of the power evolution rate equations was handled using Runge-Kutta fourth-order method [29]. Integration step along EDFA length was set to " $0.1 \mathrm{~m}$ "; spacing between wavelengths in discretized power spectra was equal to " $1 \mathrm{~nm}$." Iterative damping factor for numerical solution was " 0.7 " and convergence tolerance for numerical solution was set to " $1 \cdot 10^{-4}$." Figures $8(\mathrm{a}), 8(\mathrm{~b})$, and $8(\mathrm{c})$ show average atomicmanifold population for atomic levels $N_{1}$ and $N_{2}$ alongside the EDFA fibre. Based on the simulation (in Figure 8(b)) the Peak Power was chosen as $30 \mathrm{~mW}$. It is noteworthy that its inversion has a tendency to reach the peak in the middle of EDFA where the pump is the least distressed. Apart from that, the combined effect of signal and the front ASE (Amplified Spontaneous Emission) has the tendency to use up the inversion at the EDFA output. Figures 8(d) and 8(e) are the forward-and backward-band power solutions for the respective four-channel WDM system.

The second amplifier of the SOA type had the pump current set to "0.17 A." During simulations the spectral gain shape was set to "parabolic" and the wavelength peak gain was " $1520 \mathrm{~nm}$." The following SOA parameters were used: $\eta$ (current injection efficiency) was in the simulation set to $1.5, L$ (cavity length) is $0.5 \mathrm{~mm}, w$ (cavity width) is $3 \mu \mathrm{m}$, and $d$ (cavity thickness) is $800 \mu \mathrm{m}$. SOA model provides many options for modelling of semiconductor amplifier. Flat, parabolic, and cubic gain models are based on the following equations for the material gain and gain peak wavelength:

$$
\begin{aligned}
g(N \lambda)= & \alpha \cdot\left(N-N_{0}\right)-\alpha_{1} \cdot\left(\lambda-\lambda_{p}(N)\right)^{2}+\alpha_{3} \\
& \cdot\left(\lambda-\lambda_{p}(N)\right)^{3}, \\
\lambda_{p}(N)= & \lambda_{p 0}-\alpha_{2}\left(N-N_{\text {ref }}\right),
\end{aligned}
$$

where $\alpha$ (gain slope) is $2.78 \cdot 10^{-20} \mathrm{~m}^{2}, N_{0}$ (carrier density) is $1.4 \cdot 10^{24} \mathrm{~m}^{-3}$, and $\alpha_{1}$ and $\alpha_{3}$ (quadratic and cubic coefficients) have the value of $0 . \lambda_{p 0}$ (wavelength peak gain density) of $1552 \mathrm{~nm}$ and $\alpha_{2}$ (wavelength peak gain slope) is 0 . In our case, we have used the parabolic model where $\alpha_{3}$ has the value of 0 . The gain includes the carrier-density dependence of the peak gain wavelength and the quadratic dependence on the wavelength. This approach is very common one for dealing with an SOA spectral gain dependence. For solving the carrier 


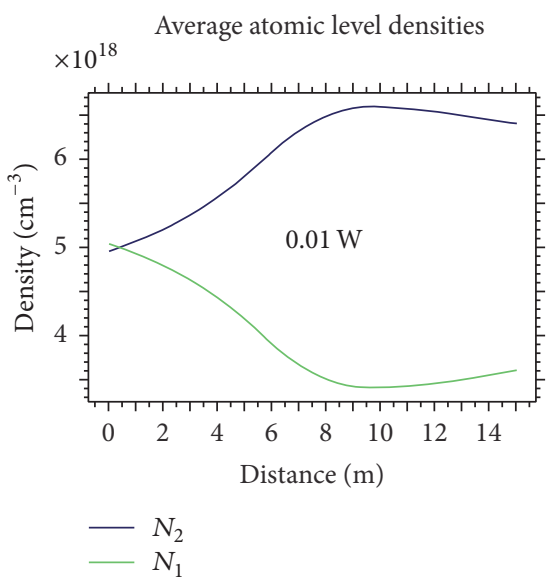

(a)

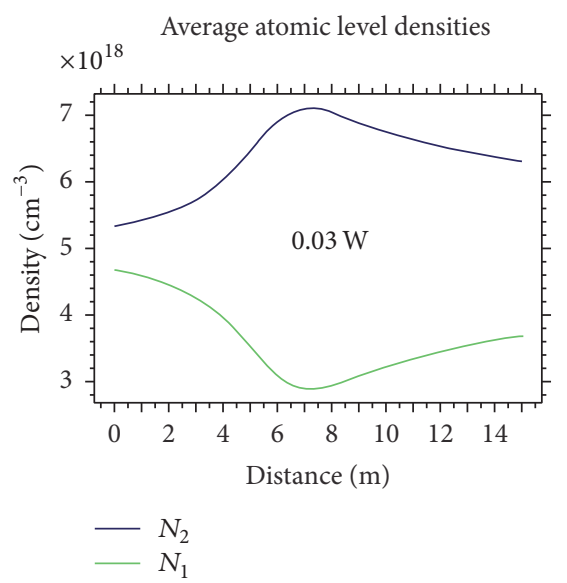

(b)

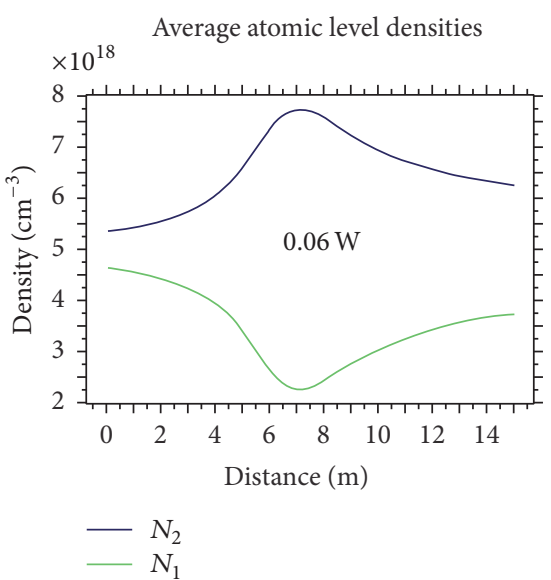

(c)

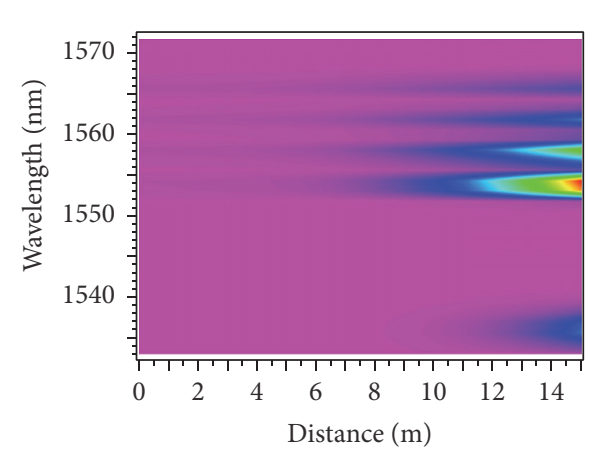

(d)
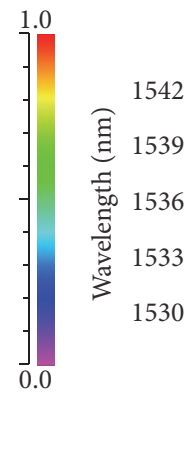

Figure 8: (a), (b), and (c) are average atomic level densities, (d) forward solution, and (e) backward solution.

rate equation, our model uses Runge-Kutta fourth-order and Adaptive Runge-Kutta fifth-order method [29].

For all simulations an optical fibre of the length " $80 \mathrm{~km}$ " was used. The overall loss was " $0.33 \mathrm{~dB} / \mathrm{km}$." In all simulations the PMD (Polarization Mode Dispersion) and SBS (Stimulated Brillouin Scattering) were ignored. The Raman effect was considered at simulations with the Raman strength model being set to "fractional" and the Raman response fraction was "0.18." The amplification of the optical signal is followed by the optical demultiplexing. Here is the overall loss of " $3 \mathrm{~dB}$ " and the filter is of type "Trapezoidal." Output of the WDM system is the optical receiver. Representation of simulated values is based on the type "Monte Carlo." In the receiver the filter is of type "Bessel" with the bandwidth of " $10 \mathrm{GHz}$." The photodetector APD has quantum efficiency of "0.8." Figure 9 is the comparison of BER for EDFA and SOA for the wavelength $1562 \mathrm{~nm}$.

Value of BER for EDFA was measured as $4.395 \cdot 10^{-6}$ which had a corresponding $Q$-factor of 4.8765. For the SOA the BER was $1.042 \cdot 10^{-5}$ with the corresponding Q-factor of 4.6808 . Figure 10 shows EDFA and SOA with wavelength of $1558 \mathrm{~nm}$.

For the EDFA the BER measurement was $1.0203 \cdot 10^{-10}$ with corresponding $Q$-factor of 6.5461. For the SOA the BER was $1.6665 \cdot 10^{-4}$ with the corresponding $Q$-factor of 4.0647 . The final values of BER and $Q$-factor for all four channels are in Table 1.
TABLE 1: Final values of BER and Q-factor for all four channels of WDM.

\begin{tabular}{lccc}
\hline Optical amplifier & Wavelength $[\mathrm{nm}]$ & BER & Q-factor \\
\hline EDFA & \multirow{2}{*}{1566} & $4.0129 \cdot 10^{-3}$ & 2.5966 \\
SOA & & $6.3464 \cdot 10^{-5}$ & 3.8744 \\
\hline EDFA & \multirow{2}{*}{1562} & $4.3905 \cdot 10^{-6}$ & 4.8765 \\
SOA & & $1.0412 \cdot 10^{-5}$ & 4.6808 \\
\hline EDFA & \multirow{2}{*}{1558} & $1.0203 \cdot 10^{-10}$ & 6.5461 \\
SOA & & $1.6665 \cdot 10^{-4}$ & 4.0647 \\
\hline EDFA & \multirow{2}{*}{1554} & $5.8535 \cdot 10^{-15}$ & 7.6987 \\
SOA & & $2.1023 \cdot 10^{-6}$ & 4.7197 \\
\hline
\end{tabular}

\section{Conclusion}

The main aim of this article is the comparison of two optical amplifiers, the EDFA and the SOA in the DWDM system. The mentioned amplifiers were evaluated based on values of BER and the related $Q$-factor. For fully optical communication systems it is good for BER to be under $10^{-12}$. In the article it is shown that the EDFA has a better error rate than the SOA. Currently the EDFA is among the most frequently used fibre amplifiers; the SOA are used mostly for their cost-effectiveness. With given simulations the wavelength of $1554 \mathrm{~nm}$ has been proven to be the best for EDFA with an 

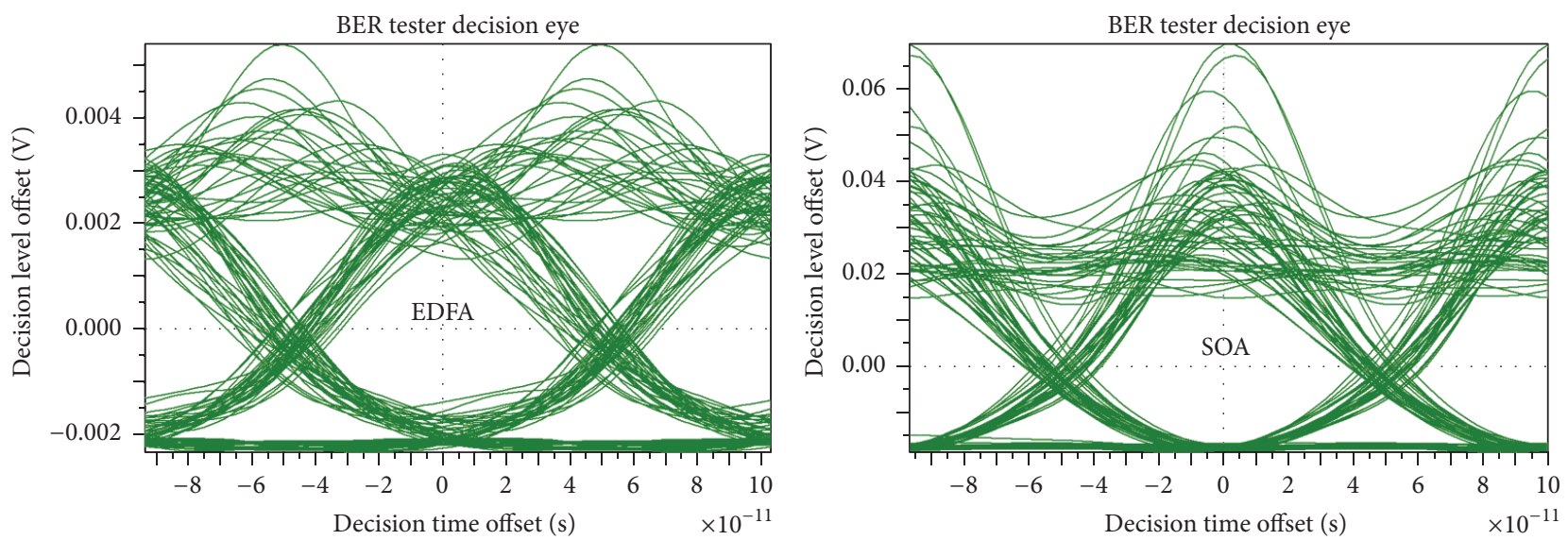

FIGURE 9: Comparison of BER for EDFA and SOA for wavelength of $1562 \mathrm{~nm}$.
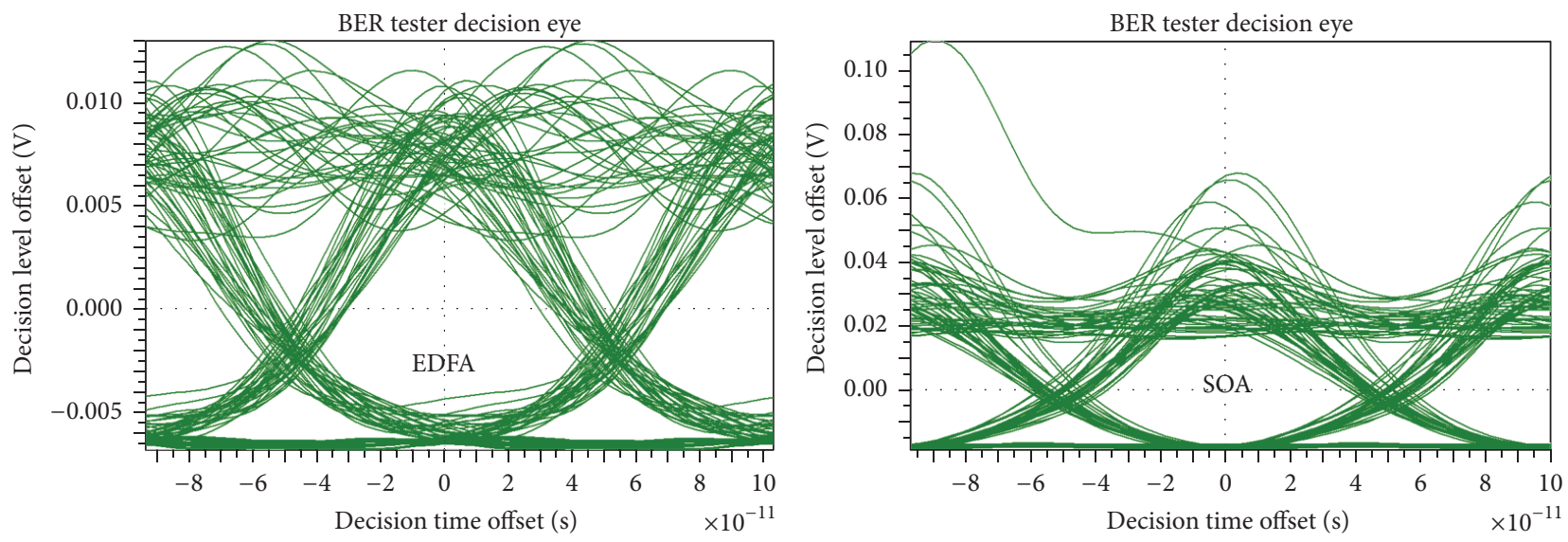

FIGURE 10: Comparison of BER for EDFA and SOA for wavelength of $1558 \mathrm{~nm}$.

error rate of around $10^{-15}$ and the wavelength of $1558 \mathrm{~nm}$ being sufficient (Figure 10) with BER of around $10^{-10}$. An insufficient error rate for EDFA was at a wavelength of $1566 \mathrm{~nm}$ and of around $10^{-3}$. For SOA, an error rate better than $10^{-6}$ was not attained, which is visible in Figure 9, and because of that it is not applicable for the given WDM system. A programme was created in Matlab (Figure 2) where it is possible to observe BER and the related $Q$-factor.

\section{Competing Interests}

The authors declare that there is no conflict of interests regarding the publication of this paper.

\section{References}

[1] J. Ruzbarsky, J. Turan, and L. Ovsenik, "Stimulated brillouin scattering in DWDM all optical communication systems," in Proceedings of the in 26th International Conference Radioelektronika (RADIOELEKTRONIKA '16), pp. 395-398, April 2016.

[2] S. Parkash, A. Sharma, H. Singh, and H. P. Singh, "Performance investigation of $40 \mathrm{~GB} / \mathrm{s}$ DWDM over free space optical communication system using RZ modulation format," Advances in Optical Technologies, vol. 2016, Article ID 4217302, 8 pages, 2016.

[3] R. Sifta, P. Munster, O. Krajsa, and M. Filka, "Symulacja ruchu dwukierunkowego w sieci typu WDM-PON," Przeglad Elektrotechniczny, vol. 90, no. 1, pp. 95-100, 2014.

[4] J. Smiesko and J. Uramova, "Access node dimensioning for IPTV traffic using effective bandwidth," Komunikacie, vol. 14, no. 2, pp. 11-16, 2012.

[5] M. Tatarko, L. Ovsenik, and J. Turan, "Properties of hybrid FSO/RF link with $60 \mathrm{GHz}$ RF backup link," in Proceedings of the 2013 36th International Convention on Information and Communication Technology, Electronics and Microelectronics (MIPRO '13), pp. 495-497, Opatija, Croatia, May 2013.

[6] O. Leclerc, P. Brindel, D. Rouvillain et al., "Dense WDM $(0.27 / \mathrm{bit} / \mathrm{s} / \mathrm{Hz}) 4 \times 40 \mathrm{Gbit} / \mathrm{s}$ dispersion-managed transmission over $10000 \mathrm{~km}$ with in-line optical regeneration by channel pairs," Electronics Letters, vol. 36, no. 4, pp. 337-338, 2000.

[7] ITU-T, "Spectral grids for WDM applications: DWDM frequency grid," Recommendation G.694.1, 2012.

[8] J. Ruzbarsky, J. Turan, and L. Ovsenik, "Effects act on transmitted signal in a fully optical fiber WDM systems," in Proceedings of the IEEE 13th International Scientific Conference on 
Informatics (INFORMATICS '15), pp. 217-221, Poprad, Slovakia, November 2015.

[9] ITU, "Spectral grids for WDM applications: CWDM frequency grid," ITU-T G.694.2, 2013.

[10] C. Chen, W.-D. Zhong, and D. Wu, "Integration of variablerate OWC with OFDM-PON for hybrid optical access based on adaptive envelope modulation," Optics Communications, vol. 381, pp. 10-17, 2016.

[11] J. Toth, M. Tatarko, L. Ovsenik, and J. Turan, "Long term availability analysis of experimental free space optics system," in Proceedings of the 22nd International Conference on Systems, Signals and Image Processing (IWSSIP '15), pp. 29-32, London, UK, September 2015.

[12] P. A. Humblet and M. Azizoglu, "On the bit error rate of lightwave systems with optical amplifiers," Journal of Lightwave Technology, vol. 9, no. 11, pp. 1576-1582, 1991.

[13] J. Tóth, L. Ovseník, and J. Turán, "Challenges in modern wireless optical communication systems-free space optics: data flow control in FSO monitoring system," in Proceedings of the 17th International Carpathian Control Conference (ICCC '16), pp. 753-756, High Tatras, Slovakia, May 2016.

[14] D. Aguiar, G. Grasso, A. Righetti, and F. Meli, "EDFA with continuous amplification of $\mathrm{C}$ and $\mathrm{L}$ bands for submarine applications," in Proceedings of the SBMO/IEEE MTT-S International Microwave and Optoelectronics Conference (IMOC '15), Porto de Galinhas, Brazil, November 2015.

[15] T. Ono, Y. Yano, K. Fukuchi et al., "Characteristics of optical duobinary signals in terabit/s capacity, high-spectral efficiency WDM systems," Journal of Lightwave Technology, vol. 16, no. 5, pp. 788-796, 1998.

[16] Y. Said and H. Rezig, "Numerical modeling and experimental investigation of the nonlinear polarization rotation phenomenon in semiconductor optical amplifiers," Advances in OptoElectronics, vol. 2011, Article ID 143235, 7 pages, 2011.

[17] P. K. Choudhury and T. Z. Khan, "Symmetric $10 \mathrm{~Gb} / \mathrm{s}$ wavelength reused bidirectional RSOA based WDM-PON with DPSK modulated downstream and OFDM modulated upstream signals," Optics Communications, vol. 372, pp. 180184, 2016.

[18] J. S. Lee, Y. C. Chung, and D. J. DiGiovanni, "Spectrumsliced fiber amplifier light source for multichannel WDM applications," IEEE Photonics Technology Letters, vol. 5, no. 12, pp. 1458-1461, 1993.

[19] J. Ahmed, A. Hussain, M. Y. Siyal, H. Manzoor, and A. Masood, "Parametric analysis of four wave mixing in DWDM systems," Optik, vol. 125, no. 7, pp. 1853-1859, 2014.

[20] T. Ivaniga, L. Ovseník, and J. Turán, "Influence of self-phase modulation on 8 and 16-channel DWDM system with NRZ and miller coding," Carpathian Journal of Electronic and Computer Engineering, vol. 8, no. 1, pp. 17-22, 2015.

[21] T. Ivaniga, L. Ovseník, and J. Turán, “The four-channel WDM system using semiconductor optical amplifier," in Proceedings of the 26th International Conference Radioelektronika (RADIOELEKTRONIKA '16), pp. 354-357, Kosice, Slovakia, April 2016.

[22] V. Bobrovs, S. Olonkins, A. Alsevska, L. Gegere, and G. Ivanovs, "Comparative performance of Raman-SOA and Raman-EDFA hybrid optical amplifiers in DWDM transmission systems," International Journal of Physical Sciences, vol. 8, no. 39, pp. 18981906, 2013.
[23] S. Olonkins, V. Bobrovs, and G. Ivanovs, "Comparison of semiconductor optical amplifier and discrete Raman amplifier performance in DWDM systems," Elektronika ir Elektrotechnika, vol. 123, no. 7, pp. 133-136, 2012.

[24] S. J. Anderson, "Comparative study of EDFA and SOA," WDM Optical Network Placed at Different Position, vol. 1, no. 1, pp. 4-6, 2015.

[25] K. Ismail, P. S. Menon, S. Shaari, A. A. Ehsan, N. Arsad, and A. A. A. Bakar, "Measurement of a post-amplified CWDM system performance with EDFA-SOA amplifiers," in Proceedings of the International Conference on Industrial Instrumentation and Control (ICIC '15), pp. 1065-1068, Pune, India, May 2015.

[26] J. Turán, L. Ovseník, and J. Turán, "Web- based multimedia courseware: applied photonics," in Proceedings of the 4th EURASIP Conference Focused on Video/Image Processing and Multimedia Communications (EC-VIP-MC '03), vol. 2, pp. 741746, Zagreb, Croatia, July 2003.

[27] W. Steingartner and V. Novitzká, "A new approach to semantics of procedures in categorical terms," in Proceedings of the 13th IEEE International Scientific Conference on Informatics (INFORMATICS '15), pp. 252-257, Poprad, Slovakia, November 2015.

[28] J. Turán and L. Ovseník, "Experimental free space optics project," in Proceedings of the 17th Symposium IMEKO TC4Measurement of Electrical Quantities, 15th International Workshop on ADC Modelling and Testing, and 3rd Symposium IMEKO TC19-Environmental Measurements, pp. 431-434, Kosice, Slovakia, September 2010.

[29] Rsoft Design Group Inc, Manual of OptSim Models Refernce, vol. 2, Block Mode, pp. 668, 2009. 


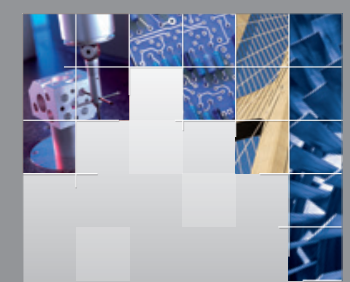

\section{Enfincering}
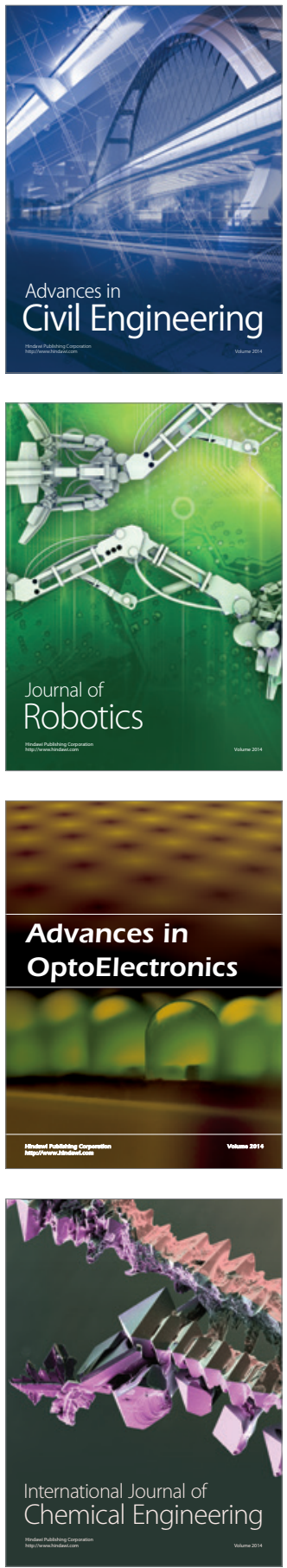

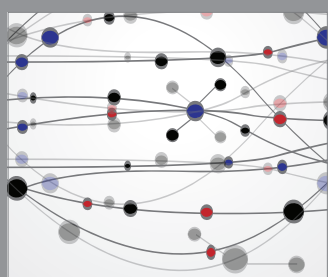

The Scientific World Journal

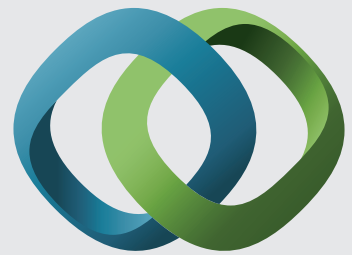

\section{Hindawi}

Submit your manuscripts at

https://www.hindawi.com
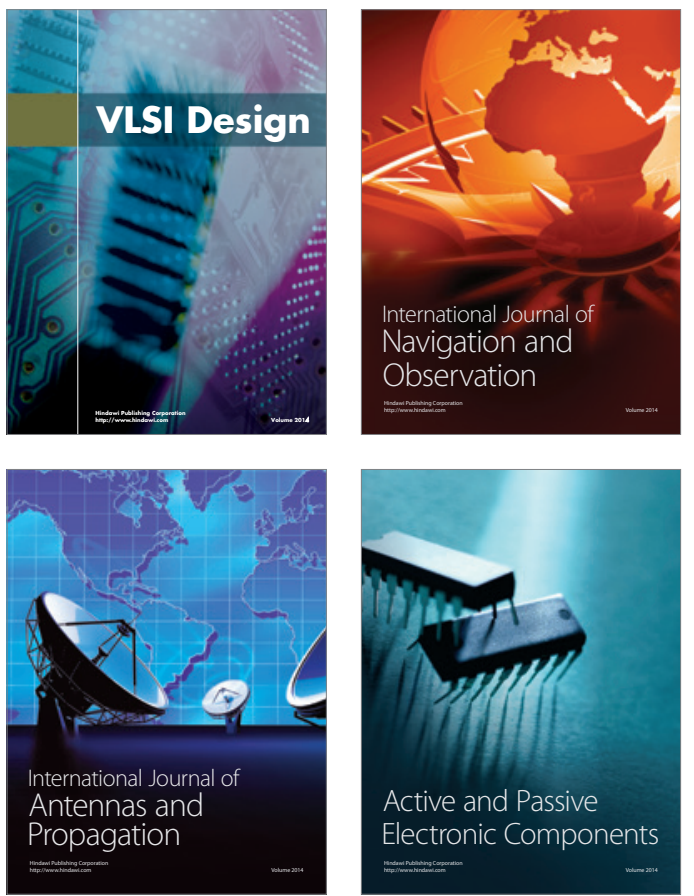
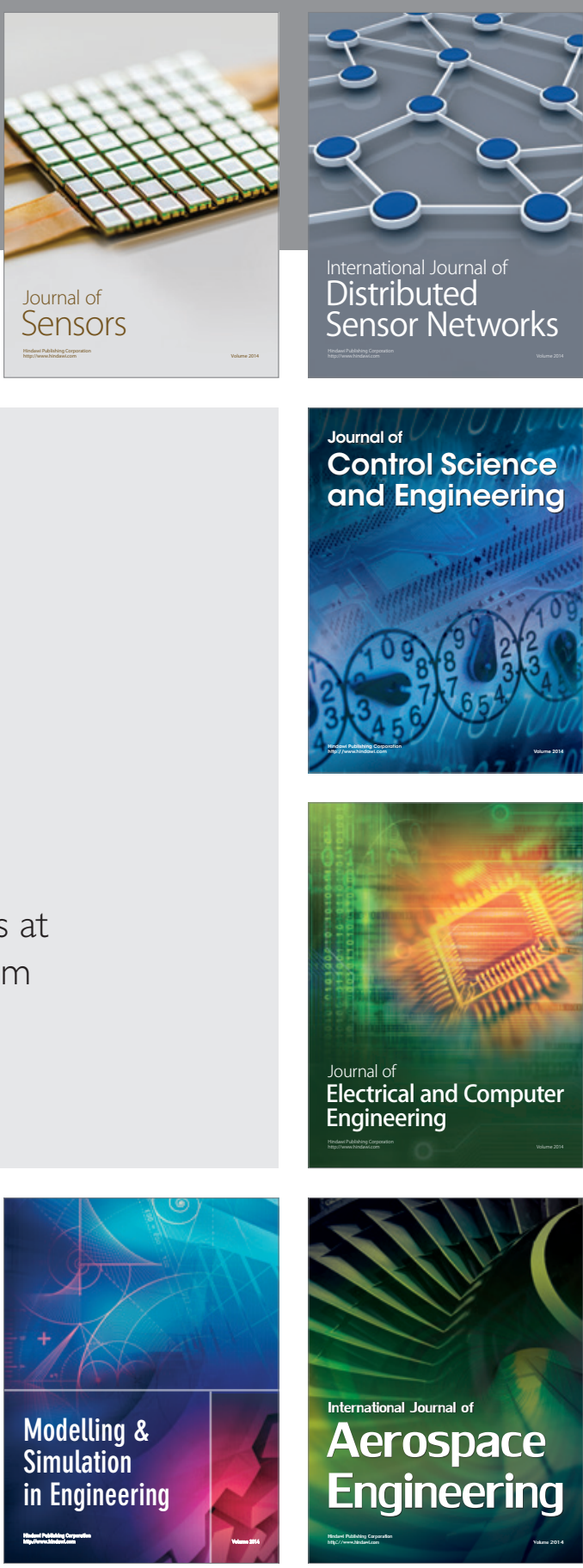

International Journal of

Distributed

Sensor Networks

$-$

Joumal of

Control Science

and Engineering
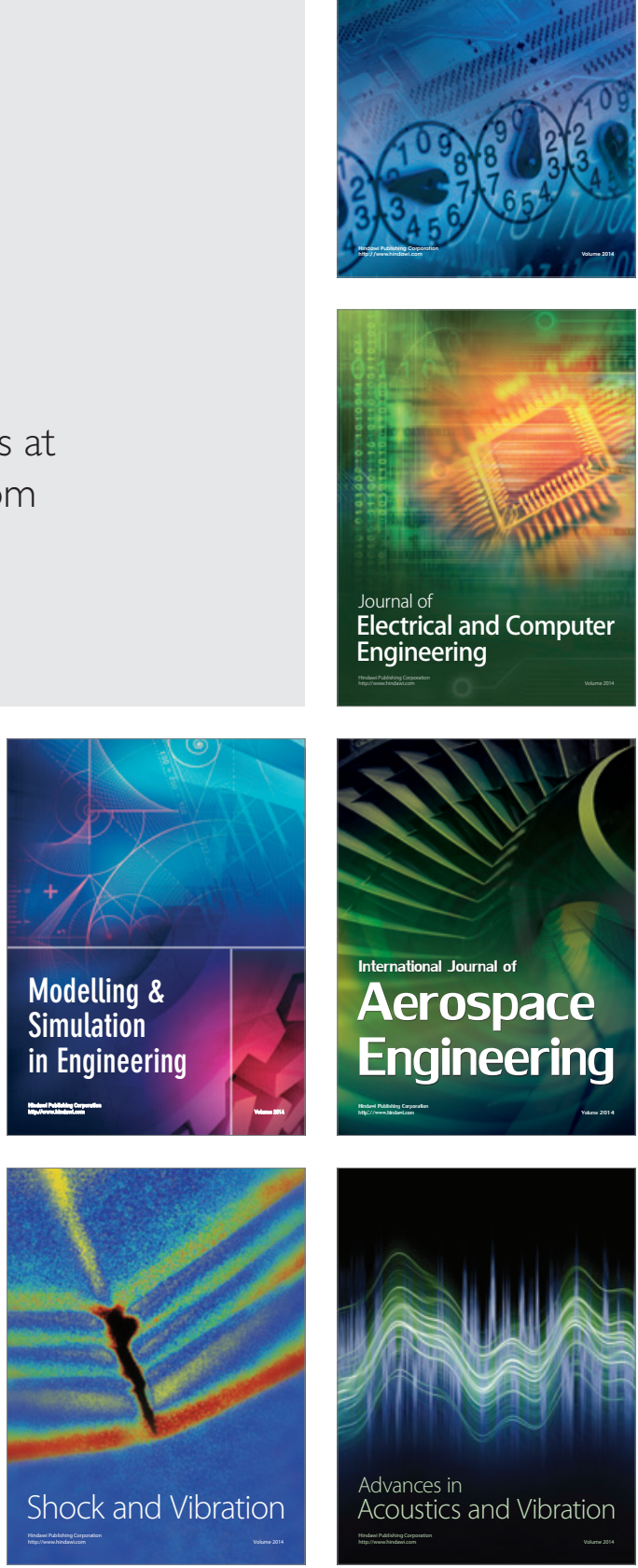